\title{
Application of an economic calculator to determine the cost of porcine reproductive and respiratory syndrome at farm-level in 21 pig herds in Germany
}

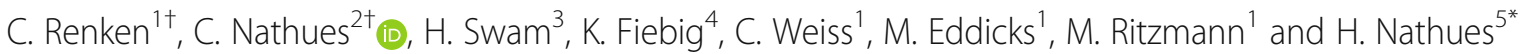

\begin{abstract}
Background: Porcine Reproductive and Respiratory Syndrome Virus (PRRSV) continues to be a major economic issue for the swine industry worldwide, not only due to acute outbreaks but also endemic infections. PRRS disease severity and consequently financial losses can vary greatly between endemically infected farms and estimation of damage is challenging. This study aimed to assess the economic effect of PRRS in a systematic way at individual farm-level for endemically infected herds, using a PRRS cost simulation tool. In total 21 German sow herds with endemic PRRSV infection were investigated. Data on health and production performance, farm management and environment to be fed into the calculator was collected on each farm, and blood samples taken to confirm the PRRSV status.
\end{abstract}

Results: All study farms experienced a significant loss attributable to PRRS. The median farm budget across all farms was $-31 €$ per sow and year, compared to a median simulated farm budget of $248 €$ if these farms had been PRRSV negative. The median total loss attributable to PRRS was $74,181 €$ per farm per year, corresponding to a median total loss per sow and year of $255 €$. The impact of PRRS on farm profits was $-19.1 \%$ on average and $-41 \%$ in the worst case.

Conclusions: The calculated losses give a good hint of the economic damage due to PRRS for the pig industry. Even in endemically infected farms, farmers face a non-negligible damage and profit from a concerted PRRS control. The calculator has proven itself in the field to render a valid estimation of losses due to PRRS in endemically infected farms.

Keywords: PPRSV endemic infection, Economic loss, Cost simulation tool, PRRS control

\section{Background}

First isolated in the Netherlands, Porcine Reproductive and Respiratory Syndrome Virus (PRRSV) impacts modern pig production worldwide, and continues to be a major economic issue for the swine industry $[1,2]$. Various economic analyses confirmed the vast financial impact of clinical outbreaks of Porcine Reproductive \& Respiratory Syndrome (PRRS) on pig production [3-7].

\footnotetext{
*Correspondence: heiko.nathues@vetsuisse.unibe.ch

${ }^{\dagger} \mathrm{C}$. Renken and C. Nathues contributed equally to this work.

${ }^{5}$ Clinic for Swine, Vetsuisse Faculty, University of Bern, Bremgartenstrasse 109a, 3012 Bern, Switzerland

Full list of author information is available at the end of the article
}

While in 2005, PRRS outbreaks in the US caused financial losses of approximately $\$ 560$ million per year, a more recent calculation in 2013 estimates the costs of productivity losses in the US due to PRRS to be as high as $\$ 664$ million per year $[3,4]$.

The epidemic form in acute outbreaks of PRRS is characterized by massive reproductive disorders in sows, perinatal losses and respiratory distress in piglets $[8,9]$. The main impact in breeding units arises from a reduction in the number of weaned piglets and a reduced farrowing rate, while in nursery and finishing pigs it arises from an increase of morbidity and mortality rates,

(c) The Author(s). 2021 Open Access This article is licensed under a Creative Commons Attribution 4.0 International License, which permits use, sharing, adaptation, distribution and reproduction in any medium or format, as long as you give appropriate credit to the original author(s) and the source, provide a link to the Creative Commons licence, and indicate if changes were made. The images or other third party material in this article are included in the article's Creative Commons licence, unless indicated otherwise in a credit line to the material. If material is not included in the article's Creative Commons licence and your intended use is not permitted by statutory regulation or exceeds the permitted use, you will need to obtain permission directly from the copyright holder. To view a copy of this licence, visit http://creativecommons.org/licenses/by/4.0/ The Creative Commons Public Domain Dedication waiver (http://creativecommons.org/publicdomain/zero/1.0/) applies to the data made available in this article, unless otherwise stated in a credit line to the data. 
reduction in feed efficiency and growth rates and therefore an increase in unmarketable pigs [3]. Furthermore, increased expenses associated with prevention and treatment of secondary infections have an indirect impact on the cost of production [3, 6]. In addition to the genetic variation of different PRRSV isolates, various management practices on-farm can influence the clinical signs of a PRRS outbreak [6]. The duration and impact of a PRRS outbreak can be highly variable among farms [3, 10]. Besides farm size further factors related to farm internal processes like pig flow, biosecurity or hygiene were proven to be associated to clinical presentation of PRRS in individual farms $[10,11]$.

Even though study results indicate that after infection, most pigs clear the PRRSV within 3 to 5 months, epidemic infection leads to individuals remaining persistently infected for several months, up to 251 days [12-14]. Summarized in a study in 2016, it can be assumed even if contagiousness decreases over time; transmission of PRRSV is possible under natural conditions up to 3 months after infection in horizontally infected pigs, and even longer in congenitally infected animals [15]. Transmission by carrier animals can lead to long-term herd infection. In 2000, a mathematical simulation estimated that the average time for type 1 PPRSV to fade-out was about 6 years in a closed herd of 115 sows, whereas it took 80 years in a herd of 230 sows [9]. Particularly in large herds with multiple cohorts a slow and uneven spread of PRRSV and consequently a long duration of infection can occur [10]. Besides its ability to persist in animals and its high transmissibility, critical limitations of PRRSV control and eradication arise from the high risk of virus introduction and the genetic variability $[16,17]$.

In contrast to an acute PRRS outbreak the endemic phase of the disease causes fewer clinical signs [5]. The economic impact of PRRS in the breeding herd is not confined to the acute phase of an outbreak [7]. In endemically infected herds, where according to Hippocrates 'endemic' means that some forms of sickness is always present in a population [18], reproductive performance can still be diminished and PRRSV can be present in the nursery for more than 2.5 years after an acute outbreak and increase susceptibility to bacterial infections $[7,19]$. Summarized by the same authors, costs attributable to a persistent PRRSV infection of growing pigs range between US\$ 6.25-15.25 per pig [7]. In 2012, a Dutch group compared data of 9 PRRS affected breeding or nucleus herds 18 weeks after an outbreak and described great variation in financial losses ranging from US\$ 3-160 per sow and year, including costs for different control strategies [5].

These studies indicate that PRRS disease severity and consequently financial losses can vary greatly between endemically infected farms and estimation of damage is challenging. Although many calculations on the impact of PRRS are available, most of them are general estimates at industry level, derived from anecdotal case reports, or consider just an epidemic period on farm [35]. The present study assesses the economic effect of PRRS in a systematic way at individual farm-level for endemically infected herds by using an economic simulation model [20]. Besides taking different disease severity levels into account, the model is easily adaptable to different farm settings and can consider the national market situation. The simulation tool should serve as a farm-level support tool for farmers and veterinarians, to assess farm profitability in the presence of PRRS and to illustrate farmers the costs of PRRS.

Based on this awareness of farm-individual financial losses due to PRRS, various control strategies are worth considering for farmers and veterinarians. Different control strategies such as vaccination or eradication are described to be effective in numerous case-reports and calculations [16, 21, 22]. Practitioners and farmers frequently ask themselves whether this also applies to their own particular case since implementing control strategies is a major investment for a farmer and it is not necessarily the most effective measure that turns out to be the most economically efficient one [23]. The presented simulation tool investigates in a second step the farmindividual efficiency of different control strategies via scenario analysis. This can simplify consulting farmers and objectify the decision which control strategy fits best in a certain farm.

The aim of the present study was to apply this simulation tool for veterinarians under field conditions and evaluate its practical applicability in the field by, in a first step, estimating losses due to an endemic PRRSV infection.

\section{Results \\ Farm data}

Data from all 21 farms were collected during individual interviews that lasted between $20 \mathrm{~min}$ and $120 \mathrm{~min}$. All farmers and farm workers, respectively, provided detailed information about the breeding part of their farm, which included production data and economic data of the last 12 months prior to the interview. In four farms, specific production data and economic data for the nursery part were not available, and in three farms no data was provided for the fattening part. Within the economic calculator determining the cost of PRRS and the economic efficiency of intervention strategies for the individual herd, default values for the German pig industry were used [20] wherever no specific value was entered into the system.

The 21 herds in this study were accommodating six different breeds: crossbreed of Large White and 
Landrace $(n=5)$, Danzucht $(n=5)$, Danish Landrace $(n=4)$, BHZP $(n=3)$, Topigs $(n=2)$, PIC $(n=1)$ and unknown $(n=1)$. Piglets were produced in batches every 1 to 5 weeks: 1-week-rhythm $(n=3)$, 2-weeks-rhythm $(n=2), 3$-weeks-rhythm $(n=10)$, 4-weeks-rhythm $(n=$ $5)$ and 5 -weeks-rhythm $(n=1)$. The suckling period was either 3 weeks $(n=7)$ or 4 weeks $(n=14)$. Other data assessed for the breeding, nursery and fattening part is summarized in Tables 1, 2 and 3.

Overall, 19 farmers used (modified) live vaccines against PRRSV either in sows only $(n=7)$ or in sows and piglets $(n=12)$ in order to prevent disease in their herd. Mass vaccination of all sows was conducted every 3 months $(n=4)$ or every 4 months $(n=8)$. The sows in the remaining herds were vaccinated at 6 days post-partum and 60 days of pregnancy $(n=3)$ or at various time points $(n=2)$; two herds did not indicate a specific scheme.

All study herds showed significant alterations in two or more of the eight health and performance parameters that PRRS is assumed to have an impact on, according to Nathues and others [20] (parameters in italic in Tables 1, 2 and 3): return-to-estrus rate (>10\%, where $10 \%$ is the upper limit for a farm considered PRRSV negative); abortion rate $(>2 \%)$; average piglets born alive (depending on genetics, $<12.7$ on average); pre-weaning mortality $(>11 \%)$; mortality in weaners $(>3 \%)$ and fatteners (1.5\%); PRRS morbidity in weaners and fatteners.

\section{Laboratory data}

Overall, 1507 blood samples were collected during the study, resulting in a median number of 73 per herd (Min: 67, Max: 74).

In 20 out of the 21 herds, PRRSV specific RNA (wild type virus) was detected by PCR in at least one of the blood samples. The mean prevalence of PRRSV independent of the age category was $14.2 \%$. Samples from gilts, weaners and growers were more often positive than samples from pigs of any other age (Fig. 1). Weaners showed a trend of being more often positive for PRRSV, when they had been vaccinated against PRRSV during their suckling period $(P=0.059)$, whereas there was no association between vaccination status of pigs and their PRRSV-status in other age categories.

Serological testing was conducted on 1357 blood samples. This fraction does not include the samples from suckling pigs of 15 herds, where maternally derived antibodies were already expected because of sow vaccination.

In all herds, antibodies against PRRSV were detected in different age categories. The within-herd seroprevalence varied between 37.9 and $98.6 \%$ with a mean of 77.3\%. Weaners at the start and at the end of their nursery period showed a lower seroprevalence when compared to other age categories (Fig. 1).

\section{Farm budget and costs of PRRS}

Revenue and costs, resulting in the farm budget (= revenue - variable costs - fixed costs, indicating the profit) were calculated for each farm in its actual status and if it was negative for PRRSV (Table 4). The median farm budget across all 21 farms was $-31 €$ per sow and year, indicating a negative profit, as opposed to a simulated farm budget of $248 €$ if the farm had been PRRSV negative. The average costs of PRRS per year were estimated comparing the actual with the 'negative' farm budget for each farm (Table 5). The median loss per sow and year across all 21 farms was $250 €$ (range 46-568 $€$, visualized in Fig. 2), which corresponds to a median total loss per farm per year of almost $75,000 €$ attributed to endemic infection with PRRSV (range 16,540-306,395 €). In all cases, the biggest part of the total loss occurred in the fattening part, whereas the lowest financial impact was observed for the nursery part. In some cases, negative costs (i.e. a surplus) were obtained for the nursery, which can be explained by a significant amount of 'costs saved' and a low amount of 'revenue foregone' (data not shown). In contrast to this, 'revenue foregone' in the fattening part, because of not raising pigs on available fattening places, resulted in significant loss and turned total farm budgets in more than $50 \%$ of the 21 farms into deficit. The overall impact of 'revenue foregone', especially because of not selling the maximal possible number of fattening pigs and the increased veterinary costs, were outweighing the 'costs saved' by consuming less feed (Fig. 3).

The impact of PRRS reduced farm profits by $-19.1 \%$ on average (SD 10) and $-41 \%$ in the worst case (the minimum was $0 \%$ ). This translates into significant loss of economic and/or normal profit, which accounts for revenue and costs including opportunity costs.

\section{Discussion}

The present study aimed to apply and evaluate the practical applicability of a PRRS economic calculator for veterinarians under field conditions by estimating losses due to endemic PRRSV infection in 21 pig farms in Germany. This is, to the authors' knowledge, the first study to apply a simulation tool in order to systematically calculate the cost of PRRS endemic infection for various different farms in a standardized and thus comparable way. Most calculations available elsewhere to date are either anecdotal, non-standardized reports from single farms, calculate the cost for the epidemic period only, and/or date from several years ago and thus do not reflect the current economic situation.

Results from this study indicate a significant loss due to PRRSV infection across farms. All farms in the study experienced a loss, and the median was 255 Euro per sow and year, ranging from 46 to 568 Euro. These 
Table 1 Farm data and economic data describing the breeding part of 21 herds endemically infected with Porcine Reproductive and Respiratory Syndrome Virus (PRRSV) and suffering from corresponding disease in sows, weaners, growers or finishing pigs

\begin{tabular}{|c|c|c|c|c|c|}
\hline Breeding & Median & Min. & Max. & Mean & $S D$ \\
\hline \multicolumn{6}{|l|}{ Farm data } \\
\hline Number of working sows in the farm per year (n) & 330 & 150 & 1200 & 355 & 215 \\
\hline Production rhythm (weeks) & 3 & 1 & 5 & 2.9 & 1.07 \\
\hline Length of suckling period (weeks) & 4 & 3 & 4 & 3.7 & 0.5 \\
\hline Replacement rate per year (\%) & 39.5 & 26.9 & 50 & 39.3 & 7.2 \\
\hline Feed consumption (gestation) / sow from insemination to farrowing (kg) & 300 & 275 & 418 & 316.8 & 42.5 \\
\hline Feed consumption (lactation) per sow during suckling period (kg) & 160 & 90 & 260 & 167 & 43.8 \\
\hline Return-to-estrus rate (\%) ${ }^{a}$ & 8.4 & 3 & 20 & 8.9 & 4.3 \\
\hline Abortions (\%) & 1.6 & 0.3 & 15 & 2.5 & 3.1 \\
\hline Piglets born alive per sow per litter $(n)^{a}$ & 15.7 & 11.7 & 18.4 & 15.4 & 1.5 \\
\hline Preweaning mortality (\%) & 13.6 & 10 & 19 & 13.7 & 2.5 \\
\hline Weight of suckling pigs at weaning $(\mathrm{kg})^{\mathrm{a}}$ & 7.4 & 5.3 & 9.5 & 7.1 & 1.1 \\
\hline \multicolumn{6}{|l|}{ Economic data } \\
\hline Price per 1000 kg gestation feed $(€)$ & 232.25 & 211.00 & 380.00 & 245.29 & 40.61 \\
\hline Price per 1000 kg lactation feed $(€)$ & 278.00 & 258.00 & 420.00 & 287.18 & 39.40 \\
\hline Veterinary cost per sow per year incl. vaccination costs $(€)$ & 193.60 & 80.00 & 250.00 & 177.02 & 47.81 \\
\hline Price per dose PRRS vaccination (sow) incl. labour (€) & 1.56 & 1.00 & 2.40 & 1.60 & 0.32 \\
\hline Price per dose PRRS vaccination (piglet) incl. labour (€) & 1.49 & 0.33 & 1.81 & 1.34 & 0.44 \\
\hline Costs for a replacement gilt $(€)$ & 350.00 & 250.00 & 400.00 & 348.40 & 39.46 \\
\hline Price per sow slaughtered / replaced $(€)$ & 240.00 & 191.00 & 500.00 & 250.69 & 69.91 \\
\hline Price per semen dose $(€)$ & 4.00 & 2.20 & 6.00 & 4.21 & 1.16 \\
\hline Energy cost per sow and year (€) & 62.50 & 40.00 & 196.00 & 73.57 & 42.73 \\
\hline Labour cost per sow and year $(€)$ & 250.00 & 131.25 & 438.00 & 244.48 & 83.13 \\
\hline Building cost per sow and year $(€)$ & 100.00 & 25.00 & 200.00 & 103.90 & 51.38 \\
\hline Equipment cost per sow and year $(€)$ & 10.00 & 5.00 & 200.00 & 44.31 & 77.20 \\
\hline Inspection, Levy and Insurance cost per sow and year (€) & 15.75 & 1.00 & 47.00 & 18.33 & 13.17 \\
\hline Transport costs for slaughter sows per sow $(€)$ & 4.40 & 0.00 & 17.00 & 4.56 & 4.55 \\
\hline Any other variable cost per sow and year $(€)$ & 0.00 & 0.00 & 0.00 & 0.00 & 0.00 \\
\hline Any other fix cost per sow and year $(€)$ & 0.00 & 0.00 & 155.80 & 9.56 & 34.40 \\
\hline
\end{tabular}

${ }^{\text {a }}$ Parameters in italic are the ones potentially altered if the farm is affected by PRRS

figures are very similar to those obtained from the same model after applying it to different hypothetical disease scenarios, indicating losses between 126 Euro and 650 Euro per sow and year depending on disease severity [20]. The fact that in the present study no association between the amount of PRRS-attributable losses in a herd and its laboratory detection rate and degree of clinical affectedness (expressed as alterations in health and performance parameters) could be seen, can be explained by the very diverse farm and general cost structures of herds enrolled in this study. This is substantiated by the very diverse estimates of farm budgets for these farms if they had been PRRSV-negative.

These resulting losses per sow and year are within the range of figures found elsewhere. In a Spanish report dating from 2013, losses during 6 months following an outbreak were estimated as being 200 US\$ per sow for a farrow-to-finish farm and 122 US\$ per sow for a breeding farm [24]. Another report from 2015 estimated costs of PRRS for chronically infected herds in UK to be 135 Euro per sow and year, whereas for the Netherlands and Denmark with $100 €$ per sow and year in acutely affected herds, estimations were somewhat lower [25]. Figures available for Germany, a projection of costs of PRRS on the whole German sow inventory (not only PRRSV infected herds), indicated an overall average of 150 Euro per sow and year [26].

Similar as in previous studies [4], the biggest loss in all study farms arose in the fattening part due to the huge revenue foregone because fewer pigs were sold. The 
Table 2 Farm data and economic data describing the nursery part of 17 herds endemically infected with PRRSV and suffering from corresponding disease in sows, weaners, growers or finishing pigs

\begin{tabular}{|c|c|c|c|c|c|}
\hline Nursery & Median & Min. & Max. & Mean & $S D$ \\
\hline \multicolumn{6}{|l|}{ Farm data } \\
\hline Time, weaners spend in the nursery (days) & 53 & 35 & 100 & 55.3 & 14.9 \\
\hline Downtime between turns in the nursery (days) & 5 & 0 & 14 & 4.9 & 3.6 \\
\hline Weight of weaners, when sold/moved to fattening (kg) & 29.3 & 22 & 50 & 30.7 & 6.4 \\
\hline$\%$ of weaners clinically affected by PRRS (including those later dying) ${ }^{a}$ & 10 & 0 & 30 & 9.1 & 7.4 \\
\hline Mortality in weaners (\%) ${ }^{\mathrm{a}}$ & 2.5 & 1.5 & 6 & 2.9 & 1.2 \\
\hline \multicolumn{6}{|l|}{ Economic data } \\
\hline Price per kg live weight of a weaner sold $(€)$ & 2.15 & 1.50 & 2.90 & 2.23 & 0.52 \\
\hline Total veterinary cost per weaner produced $(€)$ & 2.25 & 0.00 & 17.50 & 3.40 & 4.48 \\
\hline Price per 1000 kg piglet feed $(€)$ & 320.00 & 279.00 & 460.00 & 336.57 & 49.13 \\
\hline Energy cost per weaner produced $(€)$ & 0.75 & 0.00 & 62.50 & 8.71 & 21.75 \\
\hline Labour cost per weaner produced $(€)$ & 1.00 & 1.00 & 3.50 & 1.57 & 0.93 \\
\hline Building cost per weaner produced $(€)$ & 2.75 & 0.25 & 7.50 & 3.15 & 2.45 \\
\hline Equipment cost per weaner produced $(€)$ & 0.56 & 0.10 & 1.00 & 0.58 & 0.42 \\
\hline Inspection, Levy \& Insurance cost per weaner produced $(€)$ & 0.33 & 0.23 & 0.61 & 0.37 & 0.18 \\
\hline Any other variable cost per weaner produced $(€)$ & 0.00 & 0.00 & 0.00 & 0.00 & 0.00 \\
\hline Any other fix cost per weaner produced $(€)$ & 0.00 & 0.00 & 0.00 & 0.00 & 0.00 \\
\hline
\end{tabular}

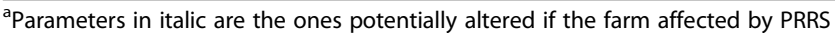

Table 3 Farm data and economic data describing the fattening part of 18 herds endemically infected with PRRSV and suffering from corresponding disease in sows, weaners, growers or finishing pigs

\begin{tabular}{|c|c|c|c|c|c|}
\hline Fattening & Median & Min. & Max. & Mean & $S D$ \\
\hline \multicolumn{6}{|l|}{ Farm data } \\
\hline Duration of fattening until pigs go to slaughter (days) & 112 & 88 & 190 & 115.6 & 21.4 \\
\hline Downtime between turns in the fattening units (days) & 5 & 2 & 15 & 5.3 & 3.5 \\
\hline Weight of fattening pigs at slaughter (kg) & 120 & 118 & 130 & 121.5 & 3.7 \\
\hline \% fatteners clinically affected by PRRS (including those later dying) ${ }^{a}$ & 10 & 0 & 50 & 13.9 & 13.7 \\
\hline Mortality in fatteners (\%) ${ }^{a}$ & 2 & 1 & 4 & 2.2 & 1 \\
\hline \multicolumn{6}{|l|}{ Economic data } \\
\hline Price per kg live weight of a fattener sold $(€)$ & 1.44 & 1.18 & 3.80 & 1.64 & 0.78 \\
\hline Total veterinary cost per fattening pig $(€)$ & 0.60 & 0.11 & 1.70 & 0.84 & 0.55 \\
\hline Fatteners' feed price per $1000 \mathrm{~kg}$ & 245.00 & 210.00 & 390.00 & 259.96 & 57.85 \\
\hline Energy cost per pig produced $(€)$ & 3.69 & 1.00 & 5.00 & 3.49 & 1.60 \\
\hline Transport cost per kg live weight slaughter pig $(€)$ & 0.027 & 0.00 & 0.05 & 0.023 & 0.016 \\
\hline Labour cost per pig produced $(€)$ & 7.30 & 3.00 & 9.00 & 5.94 & 2.79 \\
\hline Building cost per pig produced $(€)$ & 6.00 & 3.00 & 18.75 & 9.68 & 6.50 \\
\hline Equipment cost per pig produced $(€)$ & 2.00 & 0.10 & 2.44 & 1.71 & 0.92 \\
\hline Inspection, Levy and Insurance cost per pig produced $(€)$ & 0.80 & 0.10 & 2.00 & 0.90 & 0.70 \\
\hline Any other variable cost per pig produced $(€)$ & 0.00 & 0.00 & 0.90 & 0.04 & 0.20 \\
\hline Any other fix cost per pig produced $(€)$ & 0.00 & 0.00 & 10.00 & 0.57 & 2.19 \\
\hline
\end{tabular}

Parameters in italic are the ones potentially altered if the farm affected by PRRS 
Table 4 Median annual revenue, costs and resulting farm budget in Euro per sow for each herd, calculated for its actual status, and simulating that the same farm was negative for PRRSV

\begin{tabular}{|c|c|c|c|c|c|c|c|c|c|c|}
\hline \multirow{2}{*}{$\begin{array}{l}\text { Farm } \\
\text { no. }\end{array}$} & \multirow{2}{*}{$\begin{array}{l}\text { No. } \\
\text { of } \\
\text { sows }\end{array}$} & \multirow{2}{*}{ Status } & \multicolumn{8}{|l|}{ Per sow per year $(€)$} \\
\hline & & & $\begin{array}{l}\text { Revenue finishers or } \\
\text { piglets sold }\end{array}$ & $\begin{array}{l}\text { Revenue sows } \\
\text { sold }\end{array}$ & $\begin{array}{l}\text { Replacement } \\
\text { costs }\end{array}$ & $\begin{array}{l}\text { Feeding } \\
\text { costs }\end{array}$ & $\begin{array}{l}\text { Veterinary } \\
\text { costs }\end{array}$ & $\begin{array}{l}\text { Other variable } \\
\text { costs }\end{array}$ & $\begin{array}{l}\text { Fixed } \\
\text { costs }\end{array}$ & $\begin{array}{l}\text { Farm } \\
\text { budget }\end{array}$ \\
\hline \multirow[t]{2}{*}{1} & 150 & actual & 4315 & 58 & 123 & 2968 & 238 & 136 & 974 & -67 \\
\hline & & negative & 5270 & 58 & 121 & 3439 & 200 & 128 & 939 & 501 \\
\hline \multirow[t]{2}{*}{2} & 300 & actual & 3453 & 0 & 234 & 2157 & 258 & 244 & 952 & -302 \\
\hline & & negative & 4216 & 90 & 233 & 2569 & 196 & 226 & 922 & 159 \\
\hline \multirow[t]{2}{*}{3} & 178 & actual & 6635 & 90 & 137 & 3014 & 887 & 437 & 1117 & 1133 \\
\hline & & negative & 6741 & 90 & 137 & 3004 & 715 & 438 & 1098 & 1438 \\
\hline \multirow[t]{2}{*}{4} & 326 & actual & 7078 & 78 & 118 & 2614 & 166 & 466 & 1531 & 2261 \\
\hline & & negative & 7262 & 78 & 118 & 2650 & 104 & 437 & 1512 & 2519 \\
\hline \multirow[t]{2}{*}{5} & 198 & actual & 6660 & 95 & 181 & 2690 & 324 & 2536 & 2021 & -997 \\
\hline & & negative & 7093 & 95 & 181 & 2831 & 282 & 2544 & 1972 & -622 \\
\hline \multirow[t]{2}{*}{6} & 290 & actual & 4750 & 140 & 130 & 4256 & 356 & 362 & 897 & -1111 \\
\hline & & negative & 4826 & 140 & 130 & 4227 & 286 & 346 & 880 & -902 \\
\hline \multirow[t]{2}{*}{7} & 220 & actual & 4410 & 84 & 169 & 2704 & 174 & 176 & 1123 & 149 \\
\hline & & negative & 4683 & 84 & 169 & 2833 & 95 & 172 & 1107 & 392 \\
\hline \multirow[t]{2}{*}{8} & 510 & actual & 4988 & 81 & 164 & 3084 & 383 & 385 & 802 & 253 \\
\hline & & negative & 5222 & 81 & 164 & 3185 & 270 & 388 & 778 & 518 \\
\hline \multirow[t]{2}{*}{9} & 330 & actual & 4870 & 68 & 117 & 2368 & 280 & 285 & 1020 & 868 \\
\hline & & negative & 5043 & 68 & 117 & 2405 & 215 & 283 & 1002 & 1088 \\
\hline \multirow[t]{2}{*}{10} & 340 & actual & 4966 & 79 & 162 & 3402 & 265 & 274 & 942 & 1 \\
\hline & & negative & 5124 & 79 & 162 & 3443 & 172 & 276 & 924 & 226 \\
\hline \multirow[t]{2}{*}{11} & 225 & actual & 4814 & 77 & 157 & 3345 & 192 & 281 & 924 & -8 \\
\hline & & negative & 5237 & 77 & 157 & 3543 & 139 & 283 & 901 & 290 \\
\hline \multirow[t]{2}{*}{12} & $1 ' 200$ & actual & 4625 & 99 & 192 & 3231 & 135 & 273 & 901 & -7 \\
\hline & & negative & 4942 & 99 & 191 & 3347 & 112 & 269 & 873 & 248 \\
\hline \multirow[t]{2}{*}{13} & 270 & actual & 4467 & 88 & 174 & 3036 & 184 & 264 & 929 & -31 \\
\hline & & negative & 4806 & 88 & 174 & 3227 & 155 & 255 & 911 & 174 \\
\hline \multirow[t]{2}{*}{14} & 340 & actual & 4380 & 70 & 168 & 3011 & 217 & 262 & 901 & -109 \\
\hline & & negative & 4488 & 70 & 168 & 3006 & 179 & 256 & 880 & 69 \\
\hline \multirow[t]{2}{*}{15} & 350 & actual & 4239 & 72 & 134 & 2922 & 179 & 252 & 857 & -34 \\
\hline & & negative & 4657 & 72 & 134 & 3151 & 106 & 249 & 836 & 252 \\
\hline \multirow[t]{2}{*}{16} & 200 & actual & 5120 & 59 & 129 & 3596 & 450 & 268 & 913 & -178 \\
\hline & & negative & 5403 & 59 & 129 & 3730 & 325 & 272 & 896 & 110 \\
\hline \multirow[t]{2}{*}{17} & 400 & actual & 4016 & 71 & 161 & 2802 & 173 & 236 & 822 & -108 \\
\hline & & negative & 4642 & 71 & 161 & 3182 & 128 & 243 & 801 & 198 \\
\hline \multirow[t]{2}{*}{18} & 400 & actual & 5043 & 99 & 192 & 3436 & 196 & 283 & 949 & 85 \\
\hline & & negative & 5280 & 99 & 192 & 3566 & 143 & 284 & 933 & 261 \\
\hline 19 & 360 & actual & 4078 & 55 & 122 & 2791 & 175 & 246 & 872 & -73 \\
\hline & & negative & 4117 & 55 & 121 & 2811 & 159 & 241 & 867 & -27 \\
\hline 20 & 450 & actual & 4401 & 46 & 128 & 2764 & 167 & 238 & 1000 & 150 \\
\hline & & negative & 4640 & 46 & 128 & 2880 & 135 & 235 & 958 & 352 \\
\hline 21 & 408 & actual & 4320 & 76 & 150 & 2913 & 184 & 265 & 955 & -70 \\
\hline & & negative & 4615 & 76 & 148 & 3057 & 135 & 268 & 933 & 151 \\
\hline
\end{tabular}




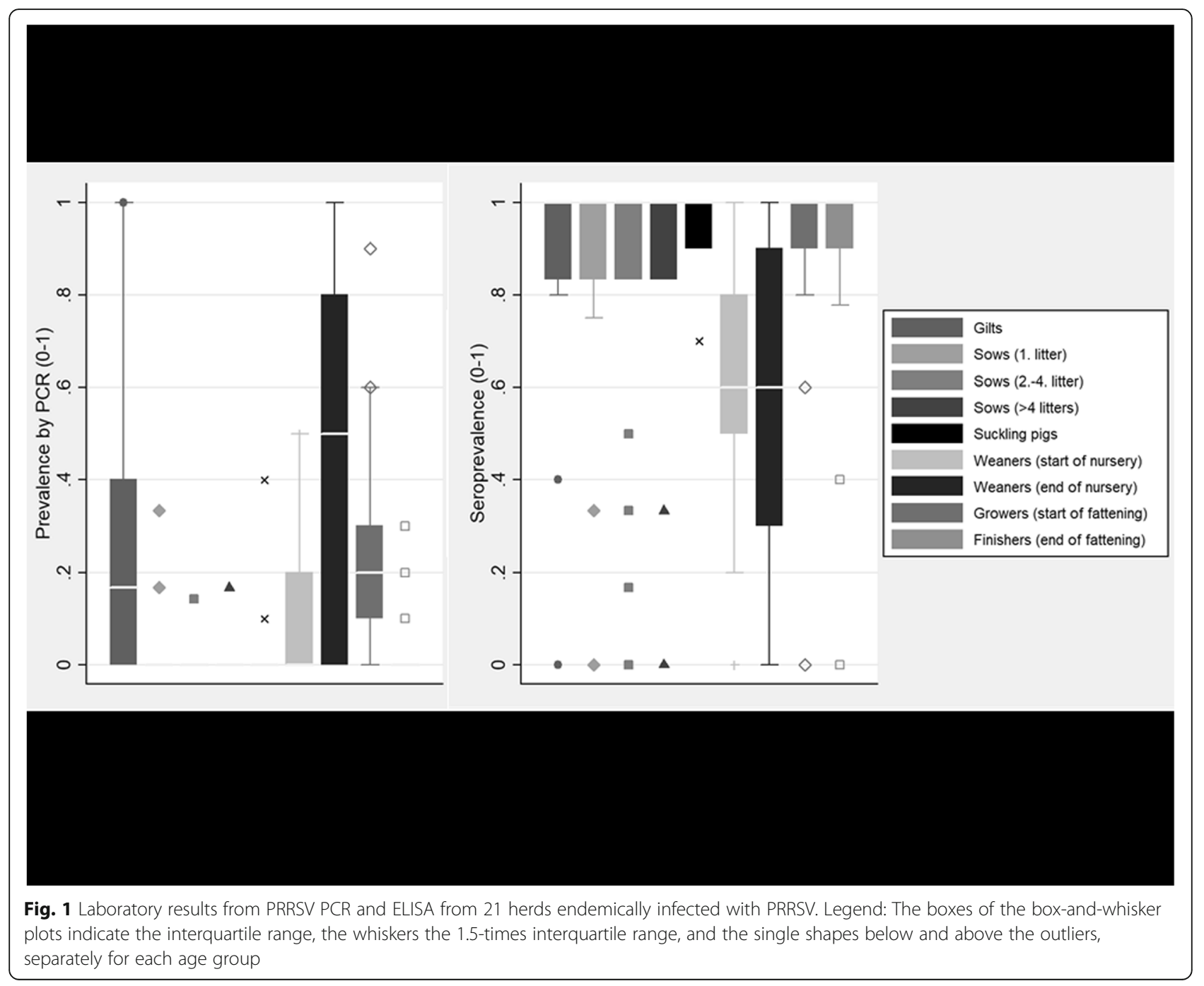

second highest impact of PRRS on the cost structure was seen on the costs for feed. All except three study farms experienced lower feeding costs than in the negative baseline scenario, because there were fewer animals to be fed. This was especially obvious in the nursery part where some farms even saved costs due to lower feed costs for fewer nursery pigs. The third highest impact of PRRS was seen on veterinary costs, where all farms had higher costs than in the negative baseline scenario. All other revenue and cost items were less affected by PRRS.

When interpreting the results it has to be kept in mind that the number of farms enrolled in the study was limited and not randomly chosen, since inclusion depended on the operation manager's willingness to participate and provide the required data. Farms were selected upon their PRRS history as reported by the herd-attending veterinarian. To substantiate that a study farm really suffered from PRRSV (endemic) infection and this could be assumed to be the main reason for financial losses, an extensive sampling for PRRSV detection (direct and indirect) was carried out on each farm. A number of roughly 60 to 70 samples per herd is considered to be sufficient to reveal the true PRRSV status of a herd. This sampling showed that indeed all study farms were exposed to PRRSV, with antibodies found in all, and wild type virus detected in all but one farm, substantiating their enduring PRRSV infection. This, together with the observed alterations in various health and performance parameters typical for PRRSV infection and not explicable by other influencing factors (e.g. management factors), make it seem very likely that estimated losses can be attributed to PRRS.

Of course, the calculation of losses due to PRRS in this economic calculator remains a simulation and the resulting figures hypothetical. A before - after comparison of farm budgets for these herds is not possible since these herds have been PRRSV infected for an unknown and certainly longer time period. Furthermore, for some of 
Table 5 Median annual loss attributable to PRRS per sow for each herd, derived from the actual farm budget minus the 'negative' farm budget from Table 4, and annual loss for the herd in total and in the breeding, nursery and fattening part

\begin{tabular}{|c|c|c|c|c|c|}
\hline \multirow{2}{*}{$\begin{array}{l}\text { Farm } \\
\text { no. }\end{array}$} & \multicolumn{5}{|c|}{ Loss per year $(€)$} \\
\hline & Per sow & Farm total & Breeding part & Nursery part ${ }^{\mathrm{a}}$ & Fattening part \\
\hline 1 & 568 & 85,263 & 8952 & -8480 & 84,791 \\
\hline 2 & 461 & 138,454 & 24,132 & $-10,587$ & 124,909 \\
\hline 3 & 305 & 54,443 & 8886 & 25,502 & 20,055 \\
\hline 4 & 258 & 84,085 & 19,958 & 10,991 & 53,136 \\
\hline 5 & 375 & 74,181 & 16,375 & -7003 & 64,809 \\
\hline 6 & 209 & 60,430 & 17,582 & 1199 & 41,649 \\
\hline 7 & 243 & 53,396 & 16,370 & 1912 & 35,113 \\
\hline 8 & 265 & 135,225 & 48,487 & 10,612 & 76,126 \\
\hline 9 & 220 & 72,661 & 19,289 & 9889 & 43,483 \\
\hline 10 & 225 & 76,447 & 32,409 & 1525 & 42,513 \\
\hline 11 & 298 & 67,246 & 12,093 & -702 & 55,854 \\
\hline 12 & 255 & 306,395 & 43,142 & 18,011 & 245,243 \\
\hline 13 & 205 & 55,312 & 9945 & 4246 & 41,121 \\
\hline 14 & 178 & 60,586 & 7443 & 16,757 & 36,386 \\
\hline 15 & 286 & 100,211 & 27,314 & -6462 & 79,360 \\
\hline 16 & 288 & 57,528 & 18,000 & 8853 & 30,674 \\
\hline 17 & 306 & 122,393 & 29,985 & $-22,956$ & 115,364 \\
\hline 18 & 176 & 70,324 & 22,298 & 6036 & 41,991 \\
\hline 19 & 46 & 16,540 & 7846 & -680 & 9375 \\
\hline 20 & 202 & 90,503 & 16,679 & 8368 & 65,456 \\
\hline 21 & 221 & 90,371 & 21,618 & -2253 & 71,006 \\
\hline Median & 255 & 74,181 & 18,000 & 1912 & 53,136 \\
\hline
\end{tabular}

${ }^{a}$ Negative values mean that the herd did not see a loss but saved costs in the nursery part

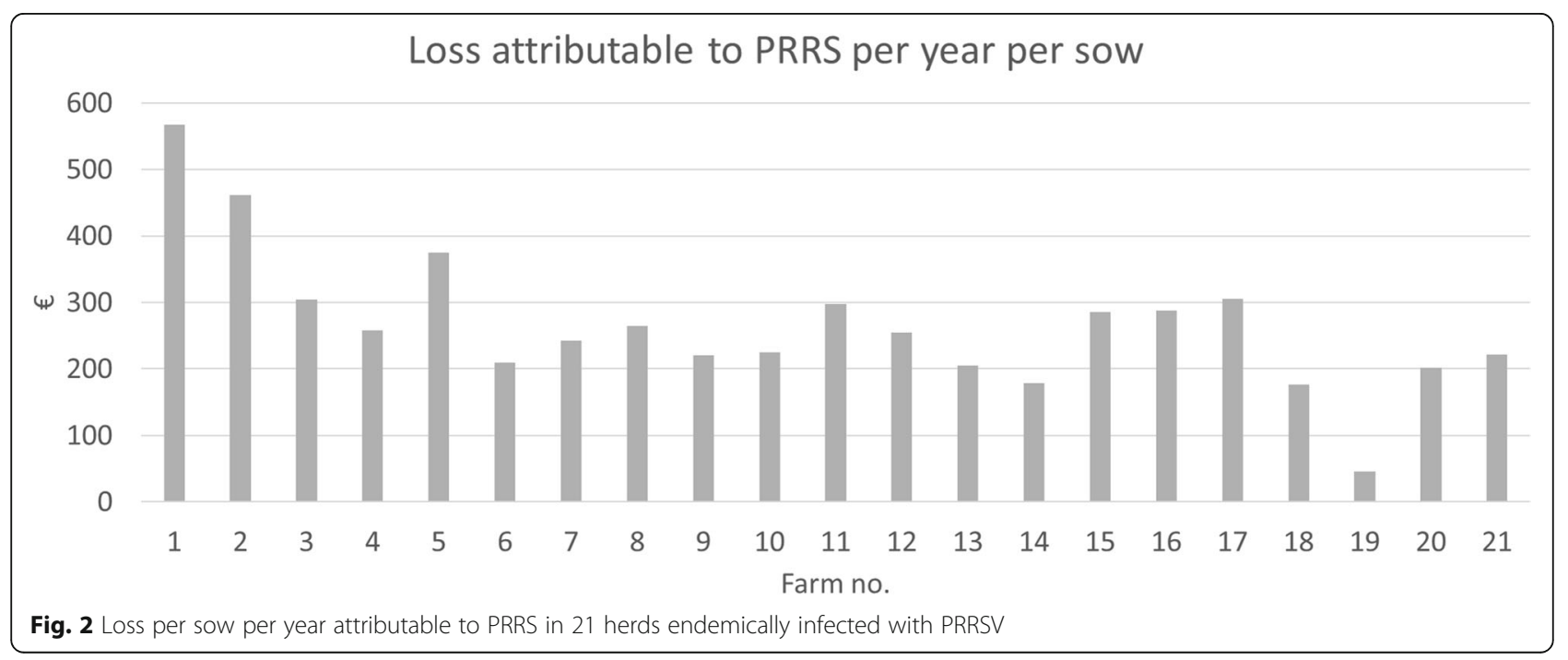




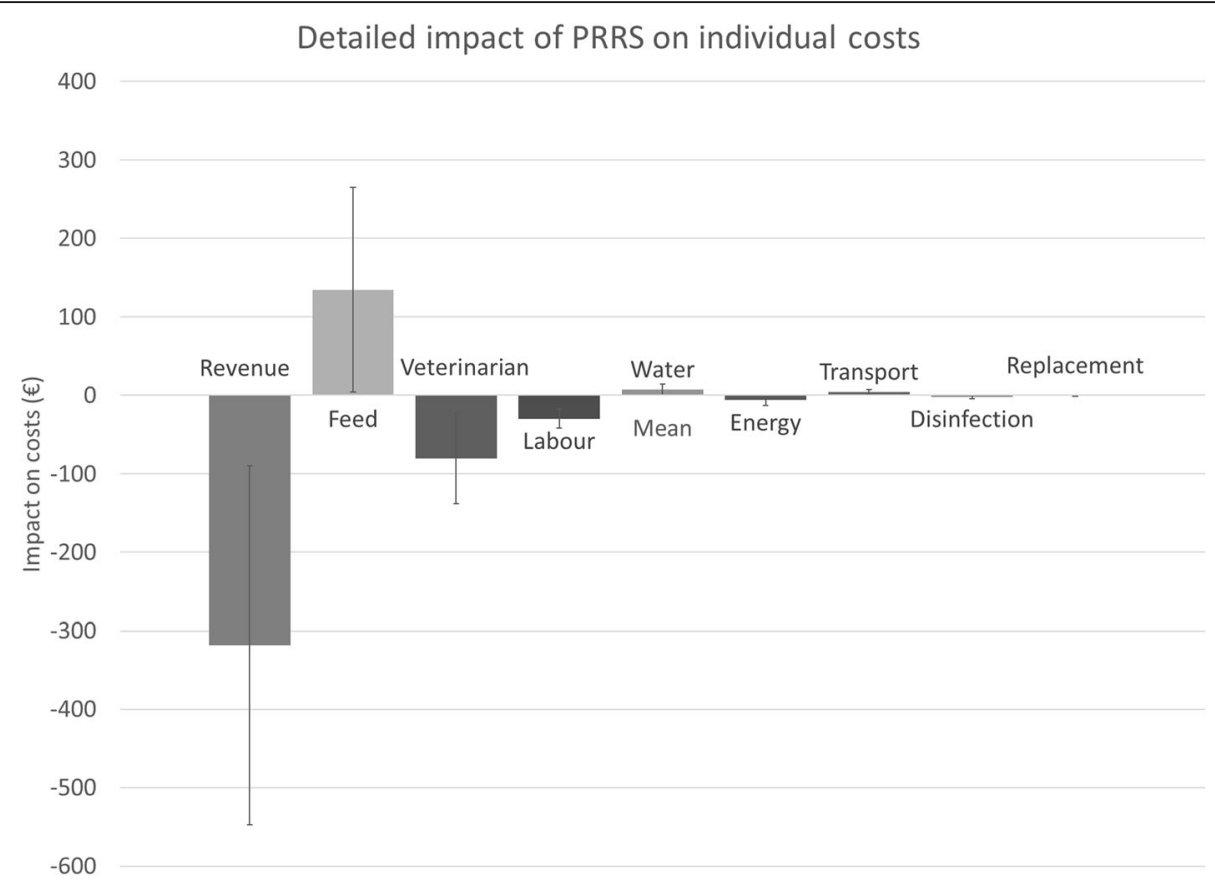

Fig. 3 Detailed impact of PRRS on individual costs in 21 herds endemically infected with PRRSV. Legend: Negative bars indicate losses; positive bars indicate costs saved

the farms the calculation might be imprecise since in the absence of available data on certain costs, standard (i.e. default) values had to be used for these cost items.

In addition, the calculation of costs of PRRS was done by deriving and comparing a hypothetical farm budget if the herd was PRRSV negative from/to the actually calculated farm budget of the respective herd. For this, several assumptions had to be made on how a 'PRRSV negative' farm would look like in terms of reference i.e. 'normal' values for health and performance parameters. Since it was not possible for all parameters to find average values specifically from confirmed PRRSV negative herds, average values from country-wide production performance data were used. These most certainly also include PRRSV positive farms. That means, the true values for PRRSV negative herds are probably even higher or better than the baseline values we used for comparison in the model. The consequence is that the model tends to underestimate the true loss and gives a conservative estimate of the costs of PRRS. Apart from that, the median simulated farm budget, i.e. profit, for a PRRSV negative farm of 260 Euro per sow and year is well in line with average farm budgets reported for German pig farms in recent years: between 100 and 300 Euro per sow and year, depending on source and year [27-29] This shows that the calculator as such renders a valid estimation of general farm economics.

Detection rates of PRRSV and antibodies within study herds were well in range of those in other studies for endemically infected herds, with generally high seroprevalences and similar age dependent distributions [30, 31]. This suggests that the herds in this study are a well representative of endemically PRRSV infected herds in general, and that the calculated PRRS-attributable losses can serve as general estimate of average losses for endemically infected herds in Germany. Since PRRSV herd prevalence in Germany is considered high, estimated around 50 to $75 \%[25,32]$ and studies indicate $30 \%$ instable herds (i.e. with virus detection in suckling pigs), this suggests that the calculated losses can be expected to occur in a big part of herds in Germany. And the situation is similar in other countries where studies estimated herd prevalence of similar magnitude, like 20$60 \%$ in Danish studies [33,34], or more than $50 \%$ in a French study [31].

Therefore, the obtained losses, although only an estimate and derived from a simulation, give a good hint of the economic scale of the damage that PRRS is causing for the (German) pig industry. It emphasizes that even in endemically infected farms, farmers face a nonnegligible economic damage due to PRRS, and that they can profit from a concerted PRRS control in their farm.

\section{Conclusions}

The calculated losses give a good hint of the economic damage due to PRRS for the pig industry. Even in endemically infected farms, farmers face a non-negligible damage and profit from a concerted PRRS control. The 
economic calculator has proven itself in the field to render a valid, conservative estimation of losses due to PRRS in endemically infected farms. The obtained costs per farm will serve as basis for the calculator to indicate the best intervention strategy for each farm. Aim of a following study will be to apply this strategy and finally evaluate its success for each study farm.

\section{Methods}

\section{PRRS herd-level cost model}

The model used in the present study to estimate the cost of PRRS in an infected farm has been established earlier by Nathues and others [20]. Consisting of three parts (breeding, nursery, fattening), the economic model can simulate production of the following different farm types: 1) breeding farms with sale of piglets at weaning; 2) breeding farms with sale of nursery pigs; 3) nursery farms; 4) fattening farms; 5) farrow-to-finish farms. Furthermore, it can be customized to farm-specific settings, production performance, disease parameters and prices, since it should serve as a decision making tool for farmers and veterinarians at individual-farm-level. 1) In a first step, the model calculates the current farm budget for the farm in question. The farm budget is defined as the farm's revenue minus its variable and fixed costs, and indicates the farm's profit. 2) In a next step, the model simulates a baseline farm budget for this farm, assuming that this farm was negative for PRRSV, by correcting for the changes in health and production performance attributable to PRRS. For this, all production and health parameters commonly affected by PRRS (the parameters in italic in Tables 1,2 and 3) are set to a baseline value that could be expected in an average, presumably healthy and PRRSV negative, farm. This means, wherever the baseline value for a parameter is better than the farm's actual value, the model uses this baseline value instead of the farm's actual value. This set of parameters as well as the corresponding baseline values were retrieved from country-specific literature on production performance. Since not for all parameters average values specifically for PRRSV negative herds were available, average values from the country's general pig population were used as a proxy [35, 36]. These baseline values are: a return-to-estrus rate of $\leq 10 \%$; an abortion rate of $\leq 2 \%$; an average number of piglets born alive (depending on genetics, $>12.7$ on average); a pre-weaning mortality of $\leq 11 \%$; a weight at weaning of $\geq 6 \mathrm{~kg}$ (with a 4 week suckling period); a mortality in weaners of $\leq 3 \%$ and fatteners of $\leq 1.5 \%$; and $0 \%$ PRRS morbidity in weaners and fatteners. Further details on this are available in the paper describing the model [20]. 3) Finally, the simulated farm budget from the negative baseline scenario is compared to the actual farm budget of the farm in question. The resulting difference is then the estimated average farm specific loss, calculated on a yearly basis, with the underlying assumption that PRRSV is the cause of the changes in productivity. The simulation tool is available via the "PRRS integrated solutions" website and smartphone app (www.integrated-prrs-solutions.com; Merck Animal Health, New Jersey, United States of America).

\section{Herd enrolment and selection criteria}

The study was carried out between April 2017 and November 2017. For demonstrating the application of the model, in total 21 farms were included, 19 one-site production systems and 2 two-site production systems with a 1:1 supply relationship (1 (one) piglet producing farm supplying 1 (one) fattening farm, which does not receive piglets from any other source). Participating farms were designated from veterinary practitioners from all over Germany matching the following criteria: herds should suffer from an endemic PRRSV infection, meaning that the herd-attending veterinarian had first and repeatedly diagnosed PRRSV infection at least 12 months prior to the study. Furthermore, they should not have epidemics of other primary infectious diseases (i.e. no clinical or laboratory confirmed diagnosis by the herd-attending veterinarian) or major flaws or changes in farm management within the last 12 months. Lastly, only farms with a minimal herd size of 100 sows and the ability to provide necessary information to run the economic disease model were included. Vaccination against PRRSV was no exclusion criterion. In detail, 14 farms were in Lower Saxony and 5 in the adjacent North of North Rhine-Westphalia, both areas with high pig density. Two of the enrolled herds were in less pig dense areas (Baden-Wuerttemberg, Thuringia).

\section{Data collection}

In advance to the sampling period, a standardized questionnaire following the structure of the calculator was developed. Data on health and production performance, farm management and environment of the PRRS affected herds were collected during a one-time farm visit from the operations manager. All questionnaires were filled by the same investigator in order to prevent any observer variation.

\section{Sample size and collection}

In the course of routine diagnostics and to evaluate the PRRSV status of the farm according to Holtkamp [37] a modified protocol was applied, where blood samples from different age groups were taken during the farm visit. The sample size for 'estimation of percentage' (i.e. prevalence estimation) was calculated based on an average number of 350 sows per herd, 25\% expected prevalence and an accepted error of 20\% (adjusted sample 
size: 18). For estimating the frequency of PRRSV infection in the offspring (infinite population size), an expected prevalence of $50 \%$ and accepted error of $20 \%$ were considered (adjusted sample size: 24). The samples were collected from the following age and production categories: incoming/mature gilts $(n=5), 18$ sows (parity $1(n=6)$, parity $2-4(n=6)$, parity $>4(n=6), 10$ suckling pigs (approx. 3 weeks of age), 10 weaners at the start of nursery (approx. 6 weeks of age), 10 weaners at the end of nursery (approx. 9 weeks of age), 10 growers (approx. 16 weeks of age) and 10 finishers (approx. 22 weeks of age). Within the different age categories, animals were selected by chance after marking individual pigs with color spray during a random walk through the pens. Pigs up to 6 weeks of age were restrained on the lap of a helping person and blood was collected by puncture of the Vena cava cranialis. Pigs older than 6 weeks were restrained by snare and sample collection was performed using Vena jugularis externa. Samples were stored $\left(7^{\circ} \mathrm{C}\right.$, at least $\left.2 \mathrm{~h}\right)$ and after centrifugation $\left(1^{\prime} 000\right.$ G, $10 \mathrm{~min}$ ) serum was transferred into reaction tubes and stored at $-20^{\circ} \mathrm{C}$ until shipment to lab.

\section{Laboratory investigation}

All blood samples were sent to the laboratory of Intervet BV in Boxmeer, Netherlands. They were tested for PRRSV antibodies using HerdCheck PRRS X3 ELISA kit manufactured by IDEXX. Besides a PRRSV PCR was executed with the virotype PRRS RT-PCR kit of Indical. Vaccine virus was detected by DV-PCR and, if present, the sample was considered 'negative for PRRSV (wild type)'. All tests were performed and evaluated according to manufacturers' instructions.

\section{Data analysis}

All information from the questionnaires was stored in Excel 2016 (Microsoft Corporation, Redmont, Washington, USA) that simultaneously enables running the model, which was developed in Excel 2010 and is utilizing @RISK software for Excel version 6.3.1 (Palisade Corporation, Newfield, New York, USA) in order to account for probability distributions of input variables. The results from the epidemiological characterization of the 21 farms and the outputs from the economic calculator after 10'000 iterations in @RISK software were summarized and submitted to descriptive statistics using STATA/IC 12.0 for Windows [64-bit $\times 86-64$ ] (StataCorp LP, Texas, USA).

\section{Abbreviations}

Max: Maximum; Min: Minimum; PRRS: Porcine Reproductive and Respiratory Syndrome; PRRSV: Porcine Reproductive and Respiratory Syndrome Virus;

SD: Standard deviation

\section{Acknowledgements}

The authors would like to thank the veterinary practitioners and the farmers for their support. Furthermore, the authors like to thank the laboratory of Intervet BV in Boxmeer and MSD Tiergesundheit GmbH.

\section{Authors' contributions}

CR conducted the investigation in the field, collected the data and contributed to drafting the manuscript. CN developed the study design and contributed to the conceptualization and analysis of the study and drafting the manuscript. HS was responsible for the laboratory analyses of samples and contributed to elaborating the manuscript. KF was responsible for the local project management and acquisition of study farms and contributed to elaborating the manuscript. CW contributed to the investigation in the field and data collection as well as revision of the manuscript. ME contributed to the supervision of the study, validation of results and revision of the manuscript. MR supervised the study and contributed to the validation of results and revision of the manuscript. HN was responsible for the conceptualization, funding acquisition and project management of the study, and contributed to data analysis and drafting the manuscript. The author(s) read and approved the final manuscript.

\section{Funding}

The trial was funded by Merck Animal Health - 556 Morris Ave - Summit, NJ 07901 - USA.

\section{Availability of data and materials}

The questionnaire and dataset used are available from the corresponding author on reasonable request.

\section{Ethics approval and consent to participate}

Blood sampling was done in the course of routine diagnostics on farm; therefore animal ethics committee approval was not required. Prior to begin of the study owner consent was obtained from all participating farmers.

\section{Consent for publication}

All authors agreed to the publication of the present manuscript.

\section{Competing interests}

All authors confirm the absence of competing interests. HS conducted the laboratory analyses under blinded conditions and KF supported in the identification of herds matching inclusion criteria, in the communication of study aims and results as well as in the interpretation of economic farm data.

\section{Author details}

'Clinic for Swine at the Centre for Clinical Veterinary Medicine, LMU Munich, Sonnenstrasse 16, 85764 Oberschleissheim, Germany. ${ }^{2}$ Veterinary Public Health Institute, Vetsuisse Faculty, University of Bern, Schwarzenburgstrasse 155, 3097 Liebefeld, Switzerland. ${ }^{3}$ Center for Diagnostic Solutions, MSD AH Boxmeer, Wim de Körverstraat 35, Boxmeer 5831 AN, The Netherlands. ${ }^{4}$ MSD Animal Health, Feldstrasse 1A, 85716 Unterschleissheim, Germany. ${ }^{5}$ Clinic for Swine, Vetsuisse Faculty, University of Bern, Bremgartenstrasse 109a, 3012 Bern, Switzerland.

Received: 13 January 2020 Accepted: 7 December 2020

Published online: 04 January 2021

\section{References}

1. Lunney JK, Benfield DA, Rowland RR. Porcine reproductive and respiratory syndrome virus: an update on an emerging and re-emerging viral disease of swine. Virus Res. 2010;154(1-2):1-6.

2. Wensvoort G, Terpstra C, Pol J, Ter Laak E, Bloemraad M, De Kluyver E, et al. Mystery swine disease in the Netherlands: the isolation of Lelystad virus. Vet Q. 1991;13(3):121-30.

3. Neumann EJ, Kliebenstein JB, Johnson CD, Mabry JW, Bush EJ, Seitzinger $\mathrm{AH}$, et al. Assessment of the economic impact of porcine reproductive and respiratory syndrome on swine production in the United States. J Am Vet Med Assoc. 2005;227(3):385-92.

4. Holtkamp DJ, Kliebenstein JB, Neumann E, Zimmerman JJ, Rotto H, Yoder TK, et al. Assessment of the economic impact of porcine reproductive and 
respiratory syndrome virus on United States pork producers. J Swine Health Prod. 2013;21(2):72.

5. Nieuwenhuis N, Duinhof TF, van Nes A. Economic analysis of outbreaks of porcine reproductive and respiratory syndrome virus in nine sow herds. Vet Rec. 2012;170(9):225.

6. Pejsak Z, Markowska-Daniel I. Losses due to porcine reproductive and respiratory syndrome in a large swine farm. Comp Immunol Microbiol Infect Dis. 1997;20(4):345-52.

7. Holck J, Polson D. The financial impact of PRRS virus. In: The porcine reproductive and respiratory syndrome compendium. 2nd ed. Des Moines: National Pork Board; 2003. p. 51-8.

8. Terpstra C, Wensvoort G, Pol J. Experimental reproduction of porcine epidemic abortion and respiratory syndrome (mystery swine disease) by infection with Lelystad vims: Koch's postulates fulfilled. Vet Q. 1991;13(3): 131-6.

9. Nodelijk G, de Jong MC, Van Nes A, Vernooy JC, Van Leengoed LA, Pol JM, et al. Introduction, persistence and fade-out of porcine reproductive and respiratory syndrome virus in a Dutch breeding herd: a mathematical analysis. Epidemiol Infect. 2000;124(1):173-82.

10. Valdes-Donoso P, Alvarez J, Jarvis LS, Morrison RB, Perez AM. Production losses from an endemic animal disease: porcine reproductive and respiratory syndrome (PRRS) in selected Midwest US sow farms. Front Vet Sci. 2018;5:102.

11. Young B, Dewey C, Poljak Z, Rosendal T, Carman S. Clinical signs and their association with herd demographics and porcine reproductive and respiratory syndrome (PRRS) control strategies in PRRS PCR-positive swine herds in Ontario. Can J Vet Res. 2010;74(3):170-7.

12. Wills RW, Doster AR, Galeota JA, Sur JH, Osorio FA. Duration of infection and proportion of pigs persistently infected with porcine reproductive and respiratory syndrome virus. J Clin Microbiol. 2003;41(1):58-62.

13. Allende R, Laegreid WW, Kutish GF, Galeota JA, Wills RW, Osorio FA. Porcine reproductive and respiratory syndrome virus: description of persistence in individual pigs upon experimental infection. J Virol. 2000;74(22):10834-7.

14. Horter DC, Pogranichniy RM, Chang CC, Evans RB, Yoon KJ, Zimmerman JJ. Characterization of the carrier state in porcine reproductive and respiratory syndrome virus infection. Vet Microbiol. 2002;86(3):213-28.

15. Pileri E, Mateu E. Review on the transmission porcine reproductive and respiratory syndrome virus between pigs and farms and impact on vaccination. Vet Res. 2016;47(1):108.

16. Holtkamp DJ, Yeske PE, Polson DD, Melody JL, Philips RC. A prospective study evaluating duration of swine breeding herd PRRS virus-free status and its relationship with measured risk. Prev Vet Med. 2010;96(3-4):186-93.

17. Murtaugh MP, Stadejek T, Abrahante JE, Lam TT, Leung FC. The everexpanding diversity of porcine reproductive and respiratory syndrome virus. Virus Res. 2010;154(1-2):18-30.

18. Swaroop S. Index of endemicity. Bull World Health Org. 1957;16:1083-101.

19. Stevenson G, Van Alstine W, Kanitz C, Keffaber K. Endemic porcine reproductive and respiratory syndrome virus infection of nursery pigs in two swine herds without current reproductive failure. J Vet Diagn Investig 1993;5(3):432-4

20. Nathues $H$, Alarcon $P$, Rushton J, Jolie R, Fiebig K, Jimenez M, et al. Cost of porcine reproductive and respiratory syndrome virus at individual farm level - an economic disease model. Prev Vet Med. 2017;142:16-29.

21. Zuckermann FA, Garcia EA, Luque ID, Christopher-Hennings J, Doster A, Brito $M$, et al. Assessment of the efficacy of commercial porcine reproductive and respiratory syndrome virus (PRRSV) vaccines based on measurement of serologic response, frequency of gamma-IFN-producing cells and virological parameters of protection upon challenge. Vet Microbiol. 2007;123(1-3):69-85.

22. Martelli P, Gozio S, Ferrari L, Rosina S, De Angelis E, Quintavalla C, et al. Efficacy of a modified live porcine reproductive and respiratory syndrome virus (PRRSV) vaccine in pigs naturally exposed to a heterologous European (Italian cluster) field strain: clinical protection and cell-mediated immunity. Vaccine. 2009:27(28):3788-99.

23. Nathues $H$, Alarcon P, Rushton J, Jolie R, Fiebig K, Jimenez M, et al. Modelling the economic efficiency of using different strategies to control porcine reproductive \& respiratory syndrome at herd level. Prev Vet Med. 2018;152:89-102.

24. Anonymous. El Impacto económico del síndrome reproductivo y respiratorio porcino. 2013. [cited 2016 Apr 11]. Available from: http://www. infopork.com/post/3894/BIENVENIDO_CReSA_A_INFOPORK.html.
25. Lehnert H. PRRS-Bekämpfung in Europa. 2016 [cited 2019 May 11]. Available from: https://www.topagrar.com/schwein/news/prrs-bekaempfung-ineuropa-9568822.html.

26. De Paz, X. PRRS cost for the European swine industry. 2015 [cited 2019 May 11]. Available from: https://www.pig333.com/articles/prrs-cost-for-theeuropean-swine-industry 10069/.

27. Arden, M. Veredelung: Wirtschaftlichkeit 17/18 über dem Schnitt, aber unter 16/17. 2018 [cited 2019 May 12]. Available from: https://www.topagrar.com/ schwein/news/veredelung-wirtschaftlichkeit-17-18-ueber-dem-schnitt-aberunter-16-17-9529311.html.

28. Schweizer, T. Wirtschaftlichkeit der Ferkelerzeugung in BW. 2016 [cited 2019 May 12]. Available from: https://alb-bw.uni-hohenheim.de/fileadmin/ einrichtungen/alb-bw/Archiv/2016/Fachgespraech/Schweizer.pdf.

29. Anonymous. LfL-Deckungsbeiträge und Kalkulationsdaten Ferkelerzeugung. 2015 [cited 2019 Jun 22]. Available from: https://www. stmelf.bayern.de/idb/ferkelerzeugungkonv.html.

30. Pileri E, Martín-Valls GE, Díaz I, Allepuz A, Simon-Grifé M, García-Saenz A, et al. Estimation of the transmission parameters for swine influenza and porcine reproductive and respiratory syndrome viruses in pigs from weaning to slaughter under natural conditions. Prev Vet Med. 2017;138: 147-55.

31. Fablet C, Marois-Créhan C, Grasland B, Simon G, Rose N. Factors associated with herd-level PRRSV infection and age-time to seroconversion in farrowto-finish herds. Vet Microbiol. 2016:192:10-20.

32. Fahrion AS, Beilage E, Nathues $H$, Dürr S, Doherr MG. Evaluating perspectives for PRRS virus elimination from pig dense areas with a risk factor based herd index. Prev Vet Med. 2014;114(3-4):247-58.

33. Lopes Antunes AC, Jensen D. Estimating time evolving cross-dependence of porcine reproduction and respiratory syndrome sero-prevalence in Danish swine herds. Prev Vet Med. 2019;167:85-9.

34. Lopes Antunes AC, Halasa T, Lauritsen KT, Kristensen CS, Larsen LE, Toft N. Spatial analysis and temporal trends of porcine reproductive and respiratory syndrome in Denmark from 2007 to 2010 based on laboratory submission data. BMC Vet Res. 2015;11:303

35. Anonymous. ZDS - Schweineproduktion 2011 in Deutschland. 20th ed. Bonn: Zentralverband der Deutschen Schweineproduktion (ZDS); 2012.

36. Anonymous. Interpig - 2013 pig cost of production in selected countries. Kenilworth: BPEX; 2014.

37. Holtkamp DJ, Polson DD, Torremorell M, Morrison B, Classen DM, Becton L, et al. Terminology for classifying the porcine reproductive and respiratory syndrome virus (PRRSV) status of swine herds. Tierarztliche Praxis Ausgabe G, Grosstiere/Nutztiere. 2011;39(2):101-12.

\section{Publisher's Note}

Springer Nature remains neutral with regard to jurisdictional claims in published maps and institutional affiliations.
Ready to submit your research? Choose BMC and benefit from:

- fast, convenient online submission

- thorough peer review by experienced researchers in your field

- rapid publication on acceptance

- support for research data, including large and complex data types

- gold Open Access which fosters wider collaboration and increased citations

- maximum visibility for your research: over $100 \mathrm{M}$ website views per year

At $\mathrm{BMC}$, research is always in progress.

Learn more biomedcentral.com/submissions 